There has been an upward climb in adult receptions under immediate sentence for violent offences with a plateau around 1986 and a recent decline starting in 1989. On 13 June 1991 there were nearly 2,900 persons serving a life sentence. This was an increase of 100 (4\%) compared with the year earlier and $73 \%$ above the figure of 13 June 1981 .

The number of those serving sentences for property offences (burglary, theft and handling, fraud and forgery) peaked in the early 1980 s and has been falling steeply in all age groups since then, particularly steeply for those aged between 17 and 20 .

Drug offenders formed 3\% of the total in 1981, 6\% in 1984 , and $9 \%$ to $10 \%$ during $1986-91$. Around $\mathbf{4 0} \%$ were sentenced for offences involving cannabis and $30 \%$ for offences involving heroin. Between mid 1987 and mid 1991 a fall of about 600 in the population of drug offenders was mainly among those sentences for unlawful supply and possession with intent supply unlawfully. The previous increase between mid 1984 and mid 1987 had occurred in these two offences and in unlawful import or export.

About 650 men (15.5\%) and about 450 women $(29 \%)$ in prison service establishments were known to be of ethnic minority origin. For men, the proportion was similar to that in 1990, having grown from $12.5 \%$ in 1986 . For women, the proportion was $1 \%$ higher than in $1990(28 \%)$, having previously increased from $17 \%$ in 1985 .

The compartmentalisation of the statistics does nothing to illuminate the psychiatric issues. We are, regrettably, only too well aware of the high proportion of people with psychiatric disturbance in prison. The failure to identify this group in any form robs the report of an appropriate focus. This is particularly regrettable with the recent interest aroused by the publication of the Reed Committee Report.

Consultant Psychiatrist and

Malcolm P. I. Weller

Honorary Senior Lecturer

St Ann's Hospital

London N15 3TH

\section{Documents and leaflets}

The Patients Charter News, a broadsheet published for the NHS Management Executive sets out to describe initiatives from round the UK purporting to make the NHS more user friendly. It lists 'Charter Fellowships' awarded for practical improvements, many in mental handicap. Although lightweight and uncritical it serves as a forum for exchange of ideas.

With so many changes in health service management, it is difficult keeping abreast with developments in our own field, let alone in other health agencies. Few are likely to find time to discover how the Patient's Charter works or what information patients really want from us.

Pendulum is published quarterly by the Manic Depression Fellowship. The issue reviewed was balanced and informative covering many topics relevant to manic depressive illness. It sets out to educate patients, families and the public about a range of issues eg. drug treatments recent research, state benefits. Some interesting articles give patients' own reviews of symptoms and treatments. A book review section covered, in this issue, Paykel's Handbook of Affective Disorders and Spike Milligan and Anthony Clare's Depression and How to Survive It! Pendulum is worth reading and I shall recommend it to patients and their families.

The Royal College of General Practitioners 'Statement on Homelessness and General Practice'-this short document raises important issues. It states that all people must have equity of access to primary care services, and GPs must provide this. Psychiatrists working with the homeless will agree that homelessness is a major contribution to physical and mental ill health, and that work with such groups should be supported. It is a pity, therefore, that the present GP contract acts as a positive disincentive emphasising high health promotion targets difficult to achieve in these populations. As a way forward GPs are urged to target homeless groups, integrating their special needs into health promotion. How such difficult outreach work will be achieved without central incentives is not clear-perhaps reports of high levels of tuberculosis rapidly spreading through the homeless will ring alarm bells at the DOH!

Consultant Psychiatrist

M. TANNAHILL

North Wales Hospital

Denbigh, Clwyd

LL16 5SS 